\title{
DESEMPENHO DE POEDEIRAS COMERCIAIS CONSUMINDO ÁGUA FILTRADA
}

\author{
N.M.S.Q. Gama1 ${ }^{1}$, H.L. da Ângela ${ }^{2}$, E.R.Freitas ${ }^{3}$, E.L. Guastalli ${ }^{1}$, C.K. Togashi ${ }^{4}$, M.R. Buim ${ }^{1}$
}

${ }^{1}$ Instituto Biológico, Centro Avançando de Pesquisa Tecnológica do Agronegócio Avícola, Unidade de Pesquisa e Desenvolvimento de Bastos, Av. Gaspar Ricardo, 1700, CEP 17690-000, Bastos, SP. E-mail: updbastos@biologico.sp.gov.br

\section{RESUMO}

\begin{abstract}
Com o objetivo de avaliar o efeito do fornecimento de água filtrada na dessedentação de aves, foram utilizadas cem poedeiras comerciais brancas com 30 semanas de idade alojadas em gaiolas equipadas com bebedouros tipo nipple, divididos em três ciclos de 21 dias cada. O delineamento experimental inteiramente casualizado foi constituído por dois tratamentos com fornecimento de água não filtrada e água filtrada e dez repetições de cinco aves por parcela. Foram coletados dados para avaliação do desempenho tais como: porcentagem de postura, consumo de ração econversão alimentar e para análise bacteriológica: coliformes fecal e total. Para avaliar a qualidade de ovos foram feitas as seguintes análises: gravidade específica, peso médio dos ovos, massa de ovos e porcentagem de casca. Os dados obtidos foram submetidos à analise de variância e teste $\mathrm{F}$ a $5 \%$ de significância. As aves que receberam água filtrada apresentaram maior percentagem de postura, maior número de ovos por ave alojada, maior massa de ovo e melhor conversão alimentar. A qualidade dos ovos não foi influenciada pelos tratamentos, no entanto, as análises realizadas constataram que a purificação da água pelo sistema de filtração melhorou a qualidade bacteriológica da água utilizada na dessedentação das aves.
\end{abstract}

PALAVRAS-CHAVE: Galinhas, qualidade de água, desempenho, qualidade dos ovos.

\section{ABSTRACT}

PERFORMANCE OF LAYING HENS WITH INTAKE OF FILTERED WATER. The objective of this study was to evaluate filtered water for the intake of laying hens. One hundred commercial laying hens with 30 weeks of age were housed in cages with nipple drinkers for 63 days divided in 3 cycles of 21 days each. This study was analyzed as a completely randomized design with 2 treatments: unfiltered water supply and filtered water supply and 10 replicates of 5 hens per pen. Data were taken on the performance percentage of egg production, feed intake and feed gain ratio $(\mathrm{kg} / \mathrm{kg}$ and $\mathrm{kg} /$ dozen $)$, bacteriological analyses of fecal and total coliform in the water, egg quality specific gravity, egg weight, egg mass and eggshell percentage. These data were submitted to analyses of variance and $\mathrm{F}$ Test at $5 \%$ of significance. The hens fed filtered water showed higher egg percentage, greater number of eggs per hen, higher egg mass and better feed-gain ratio The egg quality was not influenced by the treatments. The analyses showed that the water supplied by the purification system improved the bacteriological quality of the water used to feed the hens.

KEY WORDS: Chickens, performance, egg quality, water quality.

\section{INTRODUÇÃO}

A avicultura brasileira tem demonstrado nos últimos anos ótimo desempenho, em vista da organização e desenvolvimento do setor e dos avanços, principalmente, nas áreas de nutrição e sanidade (RISTOW;SILVA, 2006). Entretanto, a água, considerada depois do oxi- gênio o nutriente mais importante para os seres vivos e que foi designada como o nutriente esquecido por THULIN; BRUMM (1991), somente agora está recebendo a devida atenção dos técnicos da avicultura brasileira.

É amplamente reconhecida a magnitude da importância da água para todo ser vivo, sendo seu consumo diário vital para as aves de produção, que

\footnotetext{
${ }^{2}$ Médico Veterinário, autônomo, Bastos, SP, Brasil.

${ }^{3}$ Universidade Federal do Ceará, Fortaleza, CE, Brasil.

${ }^{4}$ Pólo Apta da Alta Paulista, Adamantina, SP, Brasil.
} 
sobrevivem 30 dias sem alimento e morrem assim que perdem $20 \%$ daágua presenteemseu organismo (VOHRA, 1980). Dentre todas as funções da água, a participação indispensável em todas as reações químicas, a promoção do movimento denutrientes e a retirada de substâncias tóxicas das células dos tecidos dos animais são as consideradas mais importantes pelo NATIONAL RESEARCH Council (1998). Para Leeson; Summers (2001), a água é responsável pela maioria das funções do organismo, sendo componente principal do sangue e dos fluidos extra e intracelular, é também responsável pelo transporte, absorção e digestão de nutrientes, excreção de metabólitos, pelo equilíbrio da temperatura corporal, além de outras funções importantes. A água também é utilizada na higiene das instalações e como veículo de vacinas, medicamentos e nutrientes, devendo para isso possuir constituição física, química e microbiológica adequada (GAMA, 2005).

Para a dessedentação das aves, o uso de água de qualidade química ou bacteriológica duvidosa pode interferir nos índices zootécnicos (TABLER, 2003). WATKINS (2000) relatou que os frangos criados atualmente podem ser mais susceptíveis aos problemas de qualidade de água, quando comparados aos frangos que foram criados há apenas dez anos atrás. A observação do pesquisador nos chama atenção para o rápido desenvolvimento genético a que foram submetidas as aves de produção e que estas exigem boa qualidade dos insumos utilizados para o seu crescimento e produção. KoELKEBECK (1999), ao avaliar o desempenho de poedeiras comerciais utilizando duas fontes de água, observou que aquelas poedeiras que consumiram água com altas concentrações de sais, sódio e cloretos apresentaram queda na produção de ovos, ressaltando dessa forma a importância da realização de estudos que demonstrem a garantia da água de boa qualidade para dessedentação de lotes de poedeiras comerciais. Quanto ao tipo de bebedouro, AMARAL et al. (1999) e AMARAL et al. (2001) evidenciam que o bebedouro tipo nipple protege a água de contaminação fecal, por ser um sistema fechado impedindo maior exposição da água à contaminação pelas fezes das aves e outro tipo de matéria orgânica. De acordo com CounotTe (2000), quando os resultados de análises indicam a presença de elementos e bactérias indesejáveis na água, os sistemas de filtração podem ser utilizados para purificar e, portanto, melhorar a qualidade da água de abastecimento das unidades de produção avícola. Amoroso (2009) observou que a utilização de filtros reduziu a quantidade de coliformes totais e NMP deEscherichi coli,favorecendo a qualidade microbiológica da água de bebida de frangos de corte e proporcionando melhor condição morfofisiológica e manutenção da integridade intestinal dos frangos que ingeriram água filtrada quando comparados aqueles que ingeriram água não filtrada.
Devido às características intensivas da avicultura, são de fundamental importância e essenciais o uso racional e o suprimento seguro e adequado deágua de boa qualidade, para maior eficiência da produção avícola (CARTER;SNEED, 1996). No Brasil, poucos são os relatos de estudos realizados para avaliar o desempenho produtivo das aves, de acordo com a qualidade da água ingerida.

O presente estudo teve como objetivo avaliar o desempenho produtivo e a qualidade dos ovos de poedeiras comerciais alimentadas com água filtrada através do sistema de purificação HF-1000 ${ }^{\circledR}$ desenvolvido pela Hidro Filtros do Brasil ${ }^{\circledR}$.

\section{MATERIAL E MÉTODOS}

O trabalho foi conduzido no galpão experimental da UnidadedePesquisa e Desenvolvimento de Bastos do Instituto Biológico. Foram utilizadas 100 galinhas poedeiras comerciais brancas com 30 semanas de idade. As aves foram alojadas em gaiolas de arame galvanizado $(50 \mathrm{~cm}$ de largura $x 44 \mathrm{~cm}$ decomprimento $x 40 \mathrm{~cm}$ de altura), equipadas com comedouro tipo cocho e bebedouros tipo nipple, instalados em galpões telados lateralmente e cobertos por telhas de barro. A ração utilizada foi do tipo comercial e, juntamente com a água, foi fornecida à vontade durante todo o período experimental. O experimento teve a duração de 63 dias divididos em três ciclos de 21 dias cada.

Durante todo período experimental a água que abasteceu a caixa do galpão foi captada de poço raso que continha a contaminação de $10^{4} \mathrm{UFC} / 100 \mathrm{~mL}$ de coliformes totais.

Os tratamentos consistiram no fornecimento de dois tipos de água: água não filtrada (T1) e água filtrada (T2). Cada tratamento foi composto por 10 repetições, com cinco aves cada. As aves foram pesadas e aleatoriamente distribuídas nas repetições dez dias antes do início do experimento, para adaptação.

Para o fornecimento de água filtrada, foi utilizado o sistema de purificação de água HF- $1000^{\circledR}$, composto por duas baterias de filtros paralelas e idênticas, dispostas da seguinte forma: a) um filtro de entrada (pré-filtro) produzido com o elemento filtrante Poly Flow $^{\circledR}$, que retém de partículas de 50 micras; b) um filtro intermediário (filtro) produzido com o elemento filtrante Hidro Protector ${ }^{\circledR}$, que retém partículas de cinco micras e contém a proteção antibacteriana Microban; c) um filtro de saída (filtro polidor) produzido com o elemento filtrante Hidro Pro Carbon ${ }^{\circledR} \mathrm{Com}$ retenção de partículas de cinco micras, contendo carvão ativado com retenção de cloro, remoção de cor e turbidez e a proteção antibacteriana Microban ${ }^{\circledR}$.

Os parâmetros de desempenho avaliados foram consumo de ração (g/ave/dia), percentagem de pos- 
tura(ave/dia), número deovos por avealojada (ovos/ ave alojada), massa de ovo (g/ave/dia) e conversão alimentar ( $\mathrm{kg}$ de ração/kg de ovo) e ( $\mathrm{kg}$ de ração/ dúzia de ovo).

As avaliações da qualidade dos ovos foram realizadas nos três últimos dias de cada ciclo. Os ovos de cada repetição foram coletados e identificados para determinação do peso médio (g), gravidade específica e percentagem de casca.

A avaliação da gravidade específica foi realizada pelo método de flutuação do ovo em soluções salinas de diferentes concentrações. Após essa avaliação, os ovos de cada parcela foram pesados e, em seguida, quebrados para coleta das cascas. Depois de retiradas, as cascas foram lavadas e postas para secar por 48 horas à sombra para pesagem posterior. A percentagem de casca foi determinada relacionando-se o peso da casca em relação ao peso do ovo.

A determinação de coliformes totais e fecais em amostras de água foi realizada segundo as metodologias de determinação de NMP/100 mL, descritas na Instrução Normativa do MAPA (BRASIL, 2003).

Foram colhidas sistematicamente de cada tratamento, três amostras de água por semana, durante todo período experimental. As amostras foram colhidas utilizando-se frascos e espátulas estéreis para deslocar o pendulo dos bebedouros nipple, observando-se os cuidados com a assepsia necessária para que não houvesse contaminação da amostra.

A análise estatística dos dados foi realizada utilizando-se oStatistical Analysis System (SAS $® 2001)$. Em cada período, os dados de desempenho e qualidade deovos foram submetidos à análise de variância e a diferença entre os tratamentos comparada pelo teste $\mathrm{F}(\mathrm{P}<0,05)$. A incidência de unidades com concentrações maiores do que 1.100 e menores do que três para coliformes totais e fecais entre os diferentes tratamentos foi comparada pelo teste do Quiquadrado $(\mathrm{P}<0,05)$ utilizando os dados de todas as colheitas.

\section{RESULTADOS E DISCUSSÃO}

A temperatura mínima e máxima do galpão variou de 15 a $25^{\circ} \mathrm{Ce} \mathrm{de} 26$ a $40^{\circ} \mathrm{C}$, respectivamente. Adureza eo $\mathrm{pH}$ da água fornecida às aves foram determinados e durante todo período experimental os valores se mantiveram, respectivamente, em torno de $25,5 \mathrm{mg} /$ $\mathrm{L}$ de $\mathrm{CaCO}_{3}$ e 6,5.

Os resultados de desempenho de aves alimentadas com água filtrada ou não são apresentados nas Tabelas 1 e 2 e Figura 1.

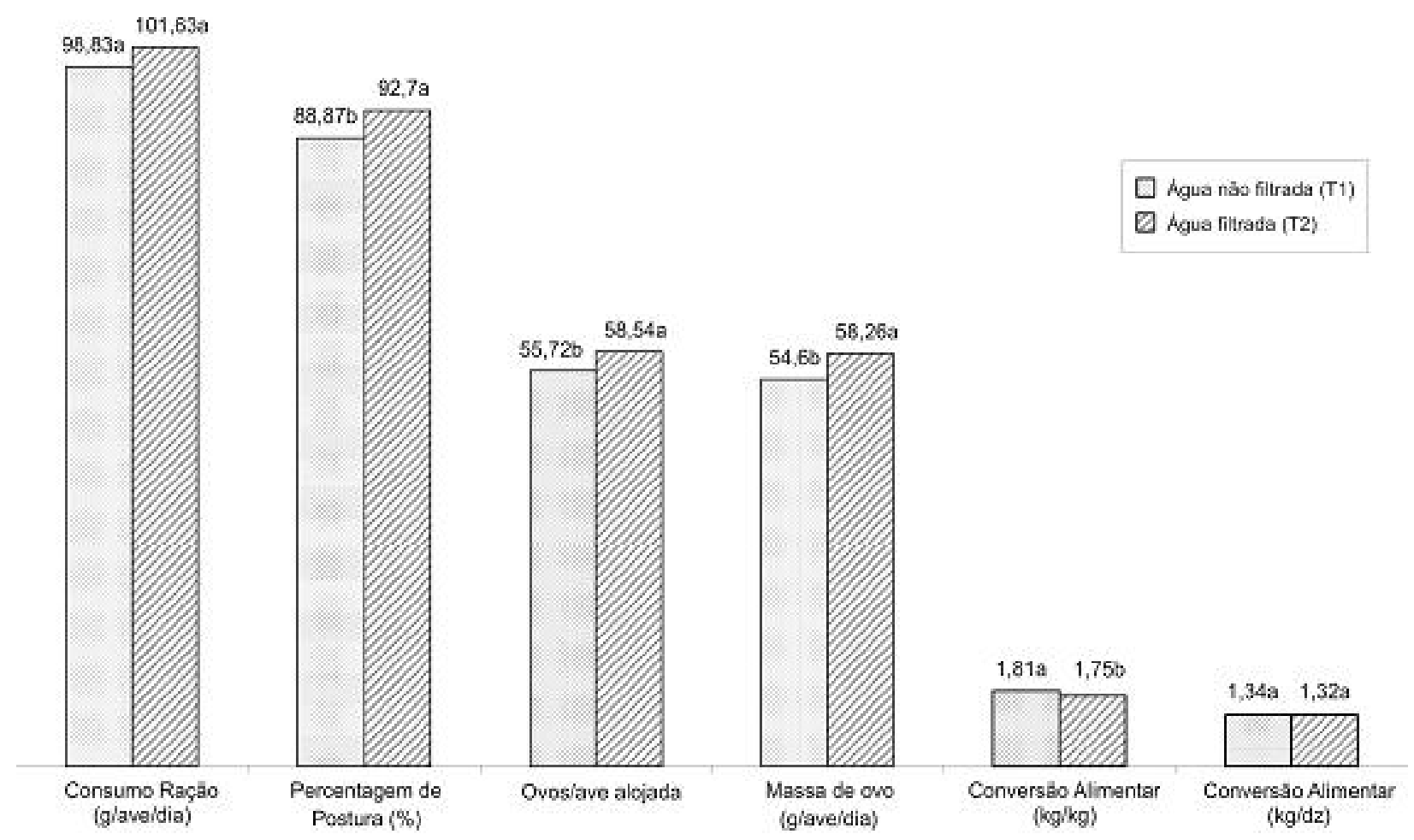

Médias, nas linhas, seguidas de letras diferentes diferem estatisticamente pelo teste $\mathrm{F}(\mathrm{P}<0,05)$.

Fig. 1 - Desempenho de galinhas poedeiras comerciais recebendo ou não com água filtrada no período total. 
Tabela 1 - Desempenho produtivo de galinhas poedeiras comerciais recebendo ou não com água filtrada em três diferentes períodos.

\begin{tabular}{|c|c|c|c|c|c|c|c|c|c|}
\hline \multirow[t]{3}{*}{ Variável } & \multicolumn{3}{|c|}{ Primeiro período } & \multicolumn{3}{|c|}{ Segundo período } & \multicolumn{3}{|c|}{ Terceiro período } \\
\hline & \multicolumn{3}{|c|}{ Tratamentos } & \multicolumn{3}{|c|}{ Tratamentos } & \multicolumn{3}{|c|}{ Tratamentos } \\
\hline & $\begin{array}{c}\text { Água não } \\
\text { filtrada }\end{array}$ & $\begin{array}{l}\text { Água } \\
\text { filtrada }\end{array}$ & $\begin{array}{l}\text { CV } \\
(\%)\end{array}$ & $\begin{array}{c}\text { Água não } \\
\text { filtrada }\end{array}$ & $\begin{array}{l}\text { Água } \\
\text { filtrada }\end{array}$ & $\begin{array}{l}\mathrm{CV} \\
(\%)\end{array}$ & $\begin{array}{c}\text { Água não } \\
\text { filtrada }\end{array}$ & $\begin{array}{l}\text { Água } \\
\text { filtrada }\end{array}$ & $\begin{array}{l}\text { CV } \\
(\%)\end{array}$ \\
\hline Consumo de ração (g/ave/dia) & $101,93 a$ & $103,28 a$ & 3,85 & $98,47 a$ & $100,76 a$ & 4,19 & $96,09 a$ & $100,85 b$ & 4,80 \\
\hline Produção de ovos (\%) & $90,10 \mathrm{a}$ & $92,19 a$ & 4,70 & $88,57 a$ & $92,57 a$ & 5,52 & $86,67 a$ & $93,33 b$ & 4,29 \\
\hline Ovos / ave alojada & $18,92 \mathrm{a}$ & $19,36 \mathrm{a}$ & 4,70 & $18,60 \mathrm{a}$ & $19,44 a$ & 5,52 & $18,20 \mathrm{a}$ & $19,60 b$ & 4,29 \\
\hline Massa de ovo (g/ave/dia) & $56,79 a$ & $59,29 a$ & 4,79 & $54,13 b$ & $57,85 a$ & 6,32 & $52,89 a$ & $57,62 b$ & 4,55 \\
\hline Conversão alimentar $(\mathrm{kg} / \mathrm{kg})$ & $1,80 \mathrm{a}$ & $1,74 b$ & 3,01 & $1,83 a$ & $1,74 b$ & 4,59 & $1,82 \mathrm{a}$ & $1,75 b$ & 5,13 \\
\hline Conversão alimentar $(\mathrm{kg} / \mathrm{dz})$ & $1,36 \mathrm{a}$ & $1,34 \mathrm{a}$ & 2,92 & $1,34 \mathrm{a}$ & $1,31 \mathrm{a}$ & 4,20 & $1,33 a$ & $1,30 \mathrm{a}$ & 3,75 \\
\hline
\end{tabular}

Médias, nas linhas, seguidas de letras diferentes diferem estatisticamente pelo teste $\mathrm{F}(\mathrm{P}<0,05)$.

Na avaliação do desempenho das aves por períodos (Tabela 1), observou-se que no primeiro período, os tratamentos influenciaram $(\mathrm{P}<0,05)$ a conversão alimentar ( $\mathrm{kg}$ de ração/ $\mathrm{kg}$ de ovo) das aves, obtendose melhor resultado para as aves que receberam o tratamento comágua filtrada. O efeito do consumo de água filtrada sobre a conversão alimentar foi confirmado por AMOROso (2009) que observou pior conversão alimentar em frangos de cortequeingeriramágua não filtrada no período de um a 14 dias deidade. Visto que a conversão alimentar $(\mathrm{kg} / \mathrm{kg})$ é a relação entre o consumo de ração e a massa de ovos uma melhor conversão era esperada, já que as aves que ingeriram água filtrada apresentaram maior percentagem de postura e maior massa de ovos.

No segundo período as aves submetidas ao tratamento com água filtrada obtiveram maior massa de ovos e apresentaram melhor conversão alimentar $(\mathrm{kg} / \mathrm{kg}$ e kg/dz) em relação às aves que receberam água não filtrada, sendo esta diferença significativa estatisticamente $(\mathrm{P}<0,05)$.

No terceiro período, com exceção da conversão alimentar medida pela razão entre $\mathrm{kg}$ de ração consumida por dúzia de ovos produzidos, todos os parâmetros avaliados foram influenciados $(P<0,05)$ pelos tratamentos. As aves que ingeriram água filtrada apresentaram maior percentagem de produção, maior número de ovos/ave alojada, maior massa de ovo e melhor conversão alimentar $(\mathrm{kg}$ ração/ $\mathrm{kg}$ de ovo), que as aves que ingeriram água não filtrada.

Nas condições em que foi realizado o presente estudo e por meio dos dados apresentados pelo tratamento com água filtrada nos três períodos, observa-se uma adaptação, isto é, o ajuste do organismo das aves à ingestão de água de melhor qualidade, revelada pelo melhor desempenho apresentado no terceiro período de avaliação, medida por cinco diferentes índices zootécnicos. Também pode ser observado que as aves do tratamento com água não filtrada apresentaram redução no consumo de ração do primeiro ao terceiro período de avaliação, podendo-se inferir que esta redução constante do consumo contribuiu para o desempenho inferior dessas aves.

JAFARI et al. (2006) relataram que uma das principais consequências da poluição fecal da água de bebida das aves é o aumento do risco de infecção por patógenos entéricos. Embora não tenhamos objetivado o estudo patológico das aves em função da contaminação fecal da água com o resultado de desempenho das aves, é necessária a condução de estudos em que se observe a presença e avalie a lesão de enterite em toda extensão do trato intestinal devido à interferência na absorção de nutrientes, consumo de ração e outros dados de desempenho. Esse fato pode ter acometido as aves do tratamento água não filtrada, resultando em menor consumo de ração e pior desempenho, ao longo dos três períodos de avaliação.

No período total (Tabela 2), as aves que receberam água filtrada apresentaram maior percentagem de postura, maior número de ovos por ave alojada, maior massa de ovo e melhor conversão alimentar $(\mathrm{kg}$ de ração/kg de ovo). O tratamento com água filtrada apresentou o melhor consumo de ração, embora não tenha sido observada diferença significativa entre o consumo médio das aves dos dois tratamentos. A menor ingestão de ração observada nas aves do tratamento com água não filtrada possivelmente influenciou negativamente as características de desempenho produtivo.

Com relação às características de qualidade de ovos, observou-se que as variáveis analisadas não foraminfluenciadas pelos tratamentos nos diferentes períodos e nem no período total. 
Tabela 2 - Desempenho de galinhas poedeiras comerciais recebendo ou não com água filtrada no período total.

\begin{tabular}{lrrr}
\hline \multirow{2}{*}{ Variáveis } & \multicolumn{3}{c}{ Tratamentos } \\
\cline { 2 - 4 } & $\begin{array}{c}\text { Água } \\
\text { não } \\
\text { filtrada }\end{array}$ & $\begin{array}{c}\text { Água } \\
\text { filtrada }\end{array}$ & CV \\
& & \\
\hline Consumo de ração (g/ave/dia) & $98,83 \mathrm{a}$ & $101,63^{\mathrm{a}}$ & 3,82 \\
Produção de ovos (\%) & $88,87 \mathrm{~b}$ & $92,70 \mathrm{a}$ & 4,51 \\
Ovos /ave alojada & $55,72 \mathrm{~b}$ & $58,54^{\mathrm{a}}$ & 4,51 \\
Massa de ovo (g/ave/dia) & $54,60 \mathrm{~b}$ & $58,26 \mathrm{a}$ & 4,60 \\
Conversão alimentar (kg/kg) & $1,81 \mathrm{a}$ & $1,75 \mathrm{~b}$ & 3,48 \\
Conversão alimentar (kg/dz) & $1,34 \mathrm{a}$ & $1,32 \mathrm{a}$ & 3,06 \\
\hline
\end{tabular}

Médias, nas linhas, seguidas de letras diferentes diferem estatisticamente pelo teste $\mathrm{F}(\mathrm{P}<0,05)$.

Tabela 3 - Determinação do número de coliformes totais e fecais (NMP/100 mL) nas amostras de água de dessedentação de galinhas poedeiras comerciais.

\begin{tabular}{lll}
\hline Variáveis & \multicolumn{2}{c}{ tratamentos } \\
\cline { 2 - 3 } & \multicolumn{1}{c}{$\begin{array}{c}\text { T1 Água não } \\
\text { filtrada }\end{array}$} & $\begin{array}{l}\text { T2 Água } \\
\text { filtrada }\end{array}$ \\
\hline \multicolumn{3}{c}{ Coliformes totais (NMP/100 mL) } \\
\hline Máximo & $>1100$ & 3,6 \\
Mínimo & 3,6 & $<3$ \\
$\mathrm{~N}^{\circ}$ de amostras $<3$ & 0 & $24^{*}(96 \%)$ \\
$\mathrm{N}^{0}$ de amostras $>1100$ & $17^{*}(68 \%)$ & 0 \\
\hline \multicolumn{3}{c}{ Coliformes Fecais $(\mathrm{NMP} / 100 \mathrm{~mL})$} \\
\hline Máximo & $>1100$ & 3,6 \\
Mínimo & $<3$ & $<3$ \\
$\mathrm{~N}^{0}$ de amostras $<3$ & $1(4 \%)$ & $24^{*}(96 \%)$ \\
$\mathrm{N}^{0}$ de amostras $>1100$ & $16^{*}(64 \%)$ & 0
\end{tabular}

*Diferente em relação ao outro tratamento de acordo com o teste do Qui-quadrado (5\%).

No que se refere à qualidade bacteriológica da água, foram realizadas contagens de coliforme total e fecal, apresentados na Tabela 3. Nenhuma amostra de água colhida no tratamento com água filtrada apresentou número de coliformes totais e fecais superiores a $1100 \mathrm{NMP} / 100 \mathrm{~mL}$, sendo que em $96 \%$ das amostras, o número de coliformes totais e fecais foi menor do que $3 \mathrm{NMP} / 100 \mathrm{~mL}$.

Nas amostras do tratamento com água não filtrada, observou-se que $68 \%$ e $64 \%$ das amostras apresentaram quantidades $>1100 \mathrm{NMP} / 100 \mathrm{~mL}$ para coliformes totais e fecais, respectivamente, e em apenas uma amostra (4\%) a contagem de coliforme fecal foi $<3 \mathrm{NMP} / 100 \mathrm{~mL}$.
A determinação do Número Mais Provável(NMP) de coliformes fecais é um indicador de contaminação fecal da água, sendo $95 \%$ destas bactérias representadas por Escherichia coli. Em se tratando de aves de exploração industrial, vários sorotipos de E. coli são patogênicos isoladamente ou associados com outros micro-orrganismos (AMARAL, 2001). Embora a água não providencie condições ideais para a multiplicação de micro-organismos patogênicos, AmARAL (2004) esclarece que estes micro-organismos são capazes de sobreviver na água por um tempo suficiente que permita a sua transmissão. $\mathrm{O}$ autor lembra ainda que a prevenção de muitas doenças nos lotes de aves pode ser feita pelo controle da qualidade bacteriológica da água ingerida, resultando em decréscimo dos custos e aumento da lucratividade, dois objetivos essenciais da produção avícola.

\section{CONCLUSÕES}

A utilização de água filtrada na dessedentação de galinhas poedeiras comerciais influenciou positivamente os parâmetros de desempenho, melhorando a conversão alimentar, aumentando a percentagem de produção de ovos e o número de ovos por ave alojada.

A purificação da água através do sistema de filtração, HF- $1000^{\oplus}$, reduziu a carga de bactérias da água de dessedentação proporcionando às aves o fornecimento de água de melhor qualidade bacteriológica.

\section{REFERÊNCIAS}

AMARAL, L.A.; ROSSI JUNIOR, O.D.; CARDOSO, V. Qualidade higiênico-sanitária da água de bebedouros pendular e nipple utilizados na criação de frangos de corte. Revista Brasileira de Ciência Avícola, v.1, n.2, p.145148, 1999.

AMARAL L.A; NADER FILHO, A; ISA, H; BARROS, L.S.S. Qualidade higiênico-sanitária e demanda de cloro da água de dessedentação de galinhas de postura coletadas em bebedouros tipo nipple e taça. Revista Brasileira de Ciência Avícola, v.3, n.3, p.249-255, 2001.

AMARAL, L.A. Drinking Water as a risk factor to poultry health. Brazilian Journal of Poultry Science, v.6, n.4, p.191-199, 2004.

AMOROSO, L. Respostas densitométricas, morfofisiológicas e desempenho de frangos de corte tratados com água filtrada e não filtrada. 2009. Tese (Doutorado) - Universidade Estadual Paulista, Faculdade de Ciências Agrárias e Veterinárias, Jaboticabal, 2009. 
BRASIL. Ministério da Agricultura Pecuária e Abastecimento. Instrução Normativa $n^{\circ}$ 62, de 26/08/2003, Seção 1, p.14. Estabelece os Métodos Analíticos e Oficiais para Análises Microbiológicas para Controle dos Produtos de Origem Animal e água. Diário Oficial [da] República Federativa do Brasil, Brasília, DF, 18 de Setembro 2003.

CARTER, T.A.; SNEED, R.E. Drinking water quality for poultry. Raleigh: North Carolina Cooperative Extension Poultry Science, 1996. (PS\&T Guide No. 42).

COUNOTTE, G. Understanding the quality of drinking water. World Poultry, v.16, n.5, p.34-40, 2000.

GAMA, N.M.S.Q. Qualidade química e bacteriológica da água utilizada em granjas produtoras de ovos. 2005. 87p. Dissertação (Doutorado em Medicina Veterinária) Universidade Estadual Paulista, Faculdade de Ciências Agrárias e Veterinárias, Jaboticabal, 2005.

JAFARI, R.A.; FAZIARA, A.; GOVAHI, M. A. Investigation into Salmonella and fecal coliform contamination of drinking water in broiler farms in Iran. International Journal of Poultry Science, v.5, n.5, p.491-493, 2006.

KOELKEBECK, K.W.; MCKEE, J.S.; HARRISON, P.C. et al. Performance of laying hens provided water from two sources. Journal Applied Poultry Research, v.8, p.374379, 1999.
LEESON, S; SUMMERS, J.D. Nutrition of chicken. 4th.ed. Guelph: University Books, 2001.

NATIONAL RESEARCH COUNCIL. US. Nutrients and toxic substances in water for livestock and poultry. Washington, DC: National Academy of Sciences, 1998.

RISTOW, L.E.; SILVA, G.M. Qualidade da água na avicultura. Ave World, n. 22, p.52-53, 2006.

SAS INSTITUTE. Statístical analisys system: system for microsoft windows, release 8.2. Cary, 2001. 1 CD-ROM.

TABLER, G.T. Water intake: a good measure of broiler performance. Avian Advise, v.5, n.3, p.7-9, 2003.

THULIN, A.J.; BRUMM, M.C. Water: The forgotten nutrient. In: MILLER, E.R.; ULLREY, D.E.; LEWIS, A.J. (Ed.). Swine nutrition. Woburn: ButterworthHeinemann, 1991. p.315-324.

VOHRA, N.P. Water quality for poultry use. Feedstuffs, v.7, p.24-25, 1980.

WATKINS, S. Water quality can influence poultry performance. Avian Advise, v. 2, n.2, p.11-12, 2000.

Recebido em 21/11/07

Aceito em 27/7/09 